\title{
Inhibition of migration and induction of apoptosis in LoVo human colon cancer cells by polysaccharides from Ganoderma lucidum
}

\author{
ZENG-ENNI LIANG ${ }^{1,2}$, YOU-JIN YI ${ }^{3}$, YU-TONG GUO ${ }^{4}$, REN-CAI WANG ${ }^{2}$, \\ QIU-LONG HU ${ }^{2}$ and XING-YAO XIONG ${ }^{2}$
}

\author{
${ }^{1}$ Hunan Agricultural Product Processing Institute, Changsha, Hunan 410128; Colleges of ${ }^{2}$ Horticulture and Landscape, \\ and ${ }^{3}$ Food Science and Technology, Hunan Agricultural University, Changsha, Hunan 410128; \\ ${ }^{4}$ State Key Laboratory of Sub-Health Intervention Technology, State Administration of \\ Traditional Chinese Medicine, Changsha, Hunan 410128, P.R. China
}

Received September 12, 2014; Accepted July 27, 2015

DOI: $10.3892 / \mathrm{mmr} .2015 .4345$

\begin{abstract}
Ganoderma lucidum polysaccharides (GLPs), which were purified from the medicinal herb G. lucidum followed by ethanol precipitation, protein depletion using the Sevage assay, purification using DEAE-cellulose (DE-52), dialysis and the use of ultrafiltration membranes, are used as an ingredient in traditional anticancer treatments in China. The aim of the current study was to evaluate the anticancer effects and investigate the underlying molecular mechanisms of GLPs on LoVo human colon cancer cells. The results demonstrated that the GLP-mediated anticancer effect in LoVo cells was characterized by cytotoxicity, migration inhibition, enhanced DNA fragmentation, morphological alterations and increased lactate dehydrogenase release. Furthermore, the activation of caspases-3,-8 and -9 was involved in GLP-stimulated apoptosis. Additionally, treatment with GLPs promoted the expression of Fas and caspase-3 proteins, whilst reducing the expression of cleaved poly(ADP-ribose) polymerase. These data indicate that GLPs demonstrate potential antitumor activity in human colon cancer cells, predominantly through the inhibition of migration and induction of apoptosis. Furthermore, activation of the Fas/caspase-dependent apoptosis pathway is involved in the cytotoxicity of GLPs.
\end{abstract}

\section{Introduction}

Colon cancer is a malignant tumor arising from the inner wall of the large intestine. It is aggressive and progresses rapidly $(1,2)$.

Correspondence to: Professor Xing-Yao Xiong or Professor Ren-Cai Wang, College of Horticulture and Landscape, Hunan Agricultural University, 1 Nongda Road, Changsha, Hunan 410128, P.R. China

E-mail: xiongxy@hunau.net

E-mail: cavepeoper@gmail.com

Key words: Ganoderma lucidum polysaccharides, human colon cancer, apoptosis, death receptor pathway
Previous epidemiological studies have indicated that the incidence rate increases with age (3). Almost $25 \%$ of cases present with metastases at the initial diagnosis and approximately half of patients with colon cancer will develop metastases, contributing to the high mortality rate of this disease (4). Furthermore, the majority of chemotherapeutic/chemopreventive agents including imatinib, doxorubicin and methotrexate have detrimental effects on patients' health (5-7). Certain natural compounds from Chinese medicinal herbs have been identified to be cytotoxic to cancer cells whilst remaining non-toxic to normal cells, including taxinol, taxanes, camptothecins, epipodophyllo, curcumin, genistein and perillyl alcohol $(8,9)$. Therefore, the evaluation and development of the anticancer activity of medicinal herbs is important for the improvement of anticancer agents. To date, the majority of polysaccharides and polysaccharide-protein complexes isolated from fungi have been reported to account for their anticancer activities in clinical therapy for patients with cancer $(10,11)$.

G. lucidum is a fungi that has been used in Asia as a health tonic to promote longevity for thousands of years (12). Polysaccharides derived from G. lucidum (GLPs) have a wide range of biological and pharmacological properties, including anticarcinoma effects, and as such have attracted attention in the biochemical and medical fields. GLPs have been demonstrated to induce suppression of cell growth and apoptosis in different types of cancer cells, with minimal negative effects on normal cells (13). Further studies have demonstrated that GLPs directly or indirectly mediate cancer cell death through diverse mechanisms (14-16). GLPs act as potential immunomodulators that indirectly inhibit cancer cells by increasing the activity of host immune cells $(14,17)$. GLPs have been demonstrated to be able to directly induce cell differentiation of leukemia cells by caspase cleavage and p53 activation (18). Additionally, GLPs may suppress Hep2 cells via the regulation of hepatic miRNAs and immune-associated miRNAs (15), and may reverse drug resistance by inhibition of the expression of resistance genes in the SKOV-3/DDP resistant ovarian cancer cell line (19). Therefore, polysaccharides from $G$. lucidum may represent a safe and effective agent in cancer therapy. In a previous study, combination treatment with GLPs and 5-fluorouracil (5-FU) resulted in synergistic 
cytotoxicity, apoptosis and cell cycle arrest in human colon cancer cells (20). However, the detailed apoptotic mechanism mediated by GLPs in human colon cancer cells remains to be fully elucidated.

In the present study, the inhibitory effect of high-molecular-weight GLPs (>10 kDa) on LoVo human colon cancer cells and the possible associated molecular mechanisms were investigated.

\section{Materials and methods}

Drugs and chemicals. Dulbecco's modified Eagle's medium (DMEM) high glucose and fetal bovine serum (FBS) were obtained from Gibco Life Technologies (Carlsbad, CA, USA). 5-FU (>99\% purity) was purchased from Shanghai Bangcheng Chemical Co., Ltd. (Shanghai, China). MTT, the Lactate Dehydrogenase (LDH) Cytotoxicity Assay kit and the Caspase-3, -8 and -9 Activity Assay kits were purchased from Beyotime Institute of Biotechnology (Nantong, China). The rabbit polyclonal primary antibodies against $\beta$-actin $(1: 4,000$; 20536-1-AP), Fas (1:1,000; 13098-1-AP) and caspase-3 (1:500; 19677-1-AP) were purchased from Proteintech Group, Inc. (Chicago, IL, USA) and the goat anti-rabbit horseradish peroxidase (HRP)-labeled secondary antibody (1:3,000; sc-2004) was purchased from Santa Cruz Biotechnology, Inc. (Dallas, TX, USA). All chemicals were of analytical grade unless otherwise specified.

Isolation and characterization of GLPs. Slices of G. lucidum (Leyss. ex. Fr.) Karst. were provided by the State Key Laboratory of Sub-Health Intervention Technology, State Administration of Traditional Chinese Medicine (Changsha, China). Samples were ground to a fine powder and refluxed in three volumes of methanol/chloroform solvent (1:2, v/v; Sinopharm Chemical Reagent Co., Ltd., Shanghai, China) and $80 \%$ ethanol three times ( $6 \mathrm{~h}$ /each time). The residues were dried, suspended in $\sim 15$ vol distilled water and were concentrated with vacuum rotary evaporator (EYELA Auto Jack NAJ-100; Tokyo Rikakikai Co., Ltd., Tokyo, Japan) vacuum filtration three times for $6 \mathrm{~h}$ each time at $95^{\circ} \mathrm{C}$. The combined concentrated solution was ethanol precipitated and then deproteinized using a Sevage assay (21). The extracts were purified using DEAE-cellulose (DE 52; Sigma-Aldrich, St. Louis, MO, USA), dialyzed with 3000 MWCO regenerated cellulose dialysis tubing (Spectrum Laboratories, Inc., Rancho Dominguez, CA, USA), concentrated and freeze-dried. The crude polysaccharides extraction yield was calculated by dividing the final weight of crude extract by the initial weight of the samples. Purified GLPs $(10 \mathrm{mg} / \mathrm{ml})$ were ultrafiltered using Biomax-500, Biomax-300, Ultracel PL-100 and Ultracel PL-30 membranes (EMD Millipore, Billerica, MA, USA) with a molecular weight cut-off of 50, 30, 10 and $3 \mathrm{kDa}$, and the five freeze-dried fractions were weighed for analysis of molecular weight composition. Three fractions of polysaccharides with high molecular weight $(>10 \mathrm{kDa})$ were pooled and further analyzed. Polysaccharide content was calculated by the phenol-sulfuric acid method (22). Protein and nucleic acid were determined by UV spectrum analysis (UV-1800; Shimadzu Corporation, Kyoto, Japan), and uronic acid was determined by the 3,5-dimethylphenol method (23). The infrared spectra were recorded with a Fourier Transform-Infrared Spectrometer
(Thermo Fisher Scientific, Madison, WI, USA) in the range of 400-4,000 $\mathrm{cm}^{-1}$. GLPs were hydrolyzed with $1 \mathrm{~mol} / \mathrm{l} \mathrm{H}_{2} \mathrm{SO}_{4}$ (Sinopharm Chemical Reagent Co., Ltd.) for $8 \mathrm{~h}$ at $100^{\circ} \mathrm{C}$, and cooled prior to centrifugation at $2,400 \mathrm{x}$ g for $30 \mathrm{~min}$ at room temperature using centrifugal filters (Amicon Ultra-4; EMD Millipore). The GLPs were then dried in the rotary evaporator, then monosaccharide components were analyzed by high-performance anion exchange chromatography on a Dionex ICS-3000 Ion Chromatograph System (Thermo Fisher Scientific).

Cell culture. The human LoVo colon carcinoma cell line was obtained from the Institute of Basic Medical Sciences (Beijing, China). Cells were maintained in DMEM high glucose supplemented with $10 \% \mathrm{FBS}$ in an incubator at $37^{\circ} \mathrm{C}$ and $5 \% \mathrm{CO}_{2}$.

Cell viability assay. LoVo cells at a density of $3 \times 10^{4}$ cells/well were cultured in 96-well plates. Following culture for $24 \mathrm{~h}$, cells were incubated with fresh medium containing various concentrations of GLPs $(0.313,0.625,1.25,2.5,5$ and $10 \mathrm{mg} / \mathrm{ml})$ at the predetermined time intervals $(24,48$ and $72 \mathrm{~h})$. A total of $50 \mu \mathrm{g} / \mathrm{ml} 5$-FU was used as a positive control, while untreated cells served as a negative control. Subsequently, $20 \mu \mathrm{l}$ MTT solution $(5 \mathrm{mg} / \mathrm{ml}$ in phosphate-buffered saline, PBS; $\mathrm{pH} 7.4$; Sinopharm Chemical Reagent Co., Ltd.) was added, followed by incubation for $4 \mathrm{~h}$ in the dark. Subsequent to the removal of the media, purple formazan crystals were dissolved in $150 \mu 1$ dimethyl sulfoxide (Beijing Solarbio Science \& Technology Co., Ltd., Beijing, China). The absorbance at $492 \mathrm{~nm}$ was measured using a microplate reader (MK3; Thermo Fisher Scientific, Waltham, MA, USA).

Scratch-wound assay. Following the formation of a cell monolayer in the 24-well plate, lines were scratched in the layer using $10 \mu 1$ pipette tips. Following the removal of non-adherent cells by PBS, adherent cells were incubated with various concentrations of GLPs $(0,0.625,1.25,2.5,5$ and $10 \mathrm{mg} / \mathrm{ml})$ for $48 \mathrm{~h}$ at $37^{\circ} \mathrm{C}(50 \mu \mathrm{g} / \mathrm{ml} \mathrm{5-FU}$ as a positive control $)$. Three different views at each concentration were imaged using an inverted microscope (IMT-2; Olympus, Tokyo, Japan) and analyzed using ImageJ software, version 1.42 (National Institutes of Health, Bethesda, MD, USA).

Electron microscopy. The GLP-treated cell suspension was fixed with $2.5 \%$ glutaraldehyde (Sigma-Aldrich) for $2 \mathrm{~h}$, followed by fixation with $1 \%$ osmium tetroxide $\left(\mathrm{OsO}_{4}\right.$; Sigma-Aldrich) for a further $2 \mathrm{~h}$. Cells were rinsed in PBS three times prior to dehydration in an ascending ethanol series $(50,70,80,90$, 95 and $100 \%$ ). Following infiltration in 50\% Quetol 651 (Nisshin EM, Tokyo, Japan) for $1 \mathrm{~h}$ and $100 \%$ Quetol 651 for $6 \mathrm{~h}$, cells were polymerized at $60^{\circ} \mathrm{C}$ for $39 \mathrm{~h}$. Samples were subsequently sectioned into $100 \mathrm{~nm}$-thick sections with a Leica UC6 microtome (Leica Microsystems, Inc., Buffalo Grove, IL, USA) and dyed with $4 \%$ uranyl acetate (Sigma-Aldrich) for $10 \mathrm{~min}$. Transmission electron microscopy (TEM) was performed using a JEOL JEM-1230 (JEOL, Ltd., Tokyo, Japan) microscope. For scanning electron microscopy (SEM; JSM-6380LV; JEOL, Ltd.), LoVo cells were exposed to different concentrations of GLPs in six-well plates for $48 \mathrm{~h}$. Subsequently, cells were fixed in $1 \%$ glutaraldehyde and $1 \% \mathrm{OsO}_{4}$, dehydrated in an ethanol 
series $(50-100 \%, \mathrm{v} / \mathrm{v})$ and dried by critical-point drying with the JSM-6380LV microscope. Following gold sputtering also with the JSM-6380LV microscope, digital images were obtained using the scanning electron microscope.

Measurement of DNA fragmentation. Cells were incubated with GLPs $(2.5,5$ and $10 \mathrm{mg} / \mathrm{ml})$ or 5 -FU $(50 \mu \mathrm{g} / \mathrm{ml})$ for $24 \mathrm{~h}$, followed by resuspension in $70 \%$ ethanol for $4 \mathrm{~h}$ at $-20^{\circ} \mathrm{C}$. Following centrifugation at $1,000 \mathrm{x}$ g for $5 \mathrm{~min}$ at $4^{\circ} \mathrm{C}$, the precipitate was dissolved in $40 \mu \mathrm{l}$ phosphate-citric acid buffer (pH 7.8; 91.5 parts $0.5 \mathrm{M} \mathrm{Na}_{2} \mathrm{HPO}_{4}$ and 8.5 parts of $0.23 \mathrm{M}$ $\mathrm{NaH}_{2} \mathrm{PO}_{4}$ ) and continuously incubated at room temperature for $45 \mathrm{~min}$ with intermittent agitation. The supernatant was mixed with $3 \mu 11 \mathrm{mg} / \mathrm{ml}$ RNaseA and $3 \mu \mathrm{l} 0.25 \% \mathrm{NP} 40$ (Beijing Solarbio Science \& Technology Co., Ltd.) at $37^{\circ} \mathrm{C}$ for $30 \mathrm{~min}$. DNA fragmentation was analyzed by gel electrophoresis on a $1.2 \%(\mathrm{w} / \mathrm{v})$ agarose gel (Sigma-Aldrich). The gel was visualized by staining with ethidium bromide (Amresco LLC, Solon, OH, USA) and the images were captured using the UVP GDS-8000 Bioimaging System (UVP, Inc. Upland, CA, USA).

$L D H$ release assay. Following culturing for $48 \mathrm{~h}$ with or without different concentrations of GLPs $(0,1.25,2.5$ and $5 \mathrm{mg} / \mathrm{ml})$, the supernatant was collected and added to a new 96-well plate (200 $\mu \mathrm{l} /$ well). Subsequently, LDH release was calculated using a LDH Cytotoxicity Assay kit according to the manufacturer's instructions. The plates were analyzed using the MK3 microplate reader at a wavelength of $450 \mathrm{~nm}$.

Measurement of caspase-3, -8 and -9 activity. The activity of caspases-3, -8 and -9 was quantified using the Caspase-3, -8 and -9 Activity kits according to the manufacturer's instructions. Briefly, cells were treated for $24 \mathrm{~h}$ with GLPs $(0,2.5$ and $5 \mathrm{mg} / \mathrm{ml})$. Following production of the pellet by centrifugation at $600 \mathrm{x}$ g for $5 \mathrm{~min}$ at $4^{\circ} \mathrm{C}$, cells were washed with PBS two times and subsequently lysed using lysis reagent (Beyotime Institute of Biotechnology) in an ice bath for $15 \mathrm{~min}$. The supernatants were incubated with $80 \mu \mathrm{l}$ reaction buffer (1\% NP-40, 20 mM Tris-HCl, pH 7.5, $137 \mathrm{mM} \mathrm{NaCl}$ and $10 \%$ glycerol; Beyotime Institute of Biotechnology) and $10 \mu \mathrm{l}$ substrate at $37^{\circ} \mathrm{C}$ for $2 \mathrm{~h}$. At the end of the incubation, the absorbance of cleavage (pNA) was measured with the MK3 microplate reader at $405 \mathrm{~nm}$.

Western blot analysis. GLP-treated cells were collected, washed with ice-cold PBS and lysed in radioimmunoprecipitation assay buffer (Applygen Technologies, Inc., Beijing, China) for $30 \mathrm{~min}$ at $4^{\circ} \mathrm{C}$. Protein concentration was determined using the Bradford assay (Bio-Rad Laboratories, Inc., Hercules, CA, USA). Total protein was subjected to electrophoresis on $12 \%$ SDS-PAGE (Beyotime Institute of Biotechnology) and transferred onto polyvinylidene fluoride membranes (EMD Millipore). Subsequently, the membranes were incubated with rabbit anti-Fas (1:1,000), rabbit anti-caspase-3 (1:500) and mouse anti- $\beta$-actin $(1: 4,000)$ at $4^{\circ} \mathrm{C}$ overnight. Membranes were then incubated with HRP-labeled secondary antibodies $(1: 3,000)$ at room temperature for $1.5 \mathrm{~h}$. The signal was detected using enhanced chemiluminescence reagents (Thermo Fisher Scientific) for western blot analysis. The relative abundance of bands was quantified using ImageJ software.

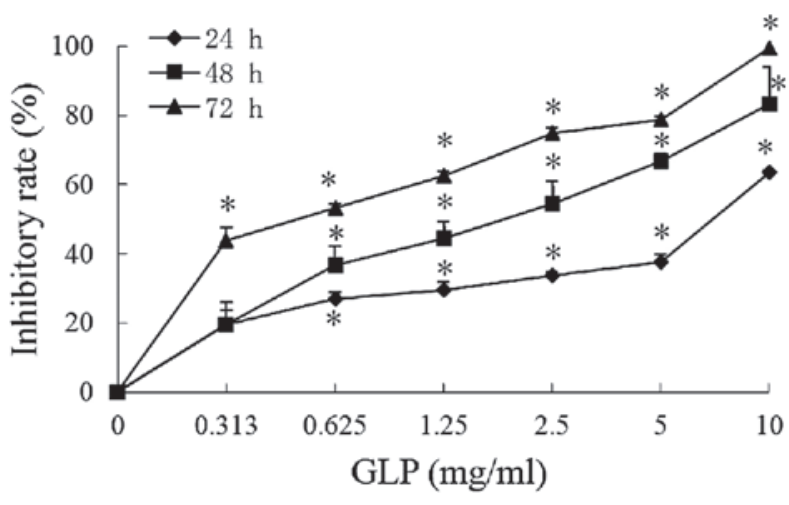

Figure 1. Effect of GLPs on inhibitory rate. Cells were treated with 0.313 $0.625,1.25,2.5,5$ and $10 \mathrm{mg} / \mathrm{ml}$ GLP for 24,48 and $72 \mathrm{~h}$. The relative inhibitory rate was determined using the following formula: [1-A490 (treated with GLP)/A490 (control)] x100\%. Data represent the mean \pm standard deviation of five experiments $(\mathrm{n}=5) ; \mathrm{P}<0.05$ vs. untreated cells. GLP, G. lucidum polysaccharide.

Statistical analysis. All data are presented as the mean \pm standard deviation. Statistical analyses were performed with Student's t-test using SPSS software, version 18.0 (SPSS, Inc., Chicago, IL, USA). P $<0.01$ was considered to indicate a statistically significant difference.

\section{Results}

Preparation of GLPs. The yield of crude polysaccharides was $\sim 3.08 \%$. The molecular weight composition of polysaccharides $>10 \mathrm{kDa}$ was: $10-30 \mathrm{kDa}, 32.1 \%$; 30-50 kDa, 21.8\%; and $>50 \mathrm{kDa}, 46.1 \%$. Using UV scanning, the absence of nucleic acids and proteins in the GLPs was indicated by minimal absorption at 260 and $280 \mathrm{~nm}$. GLPs were comprised of $89 \%$ carbohydrate and $11 \%$ uronic acid. The peaks of infrared spectroscopy at 847 and $922 \mathrm{~cm}^{-1}$ indicated that the purified GLPs predominantly consisted of $\alpha$-polysaccharides (24). The results of the monosaccharide composition analysis were in agreement and indicated that GLPs were composed of arabinose, galactose, glucose and cellose at the molar ratios of 11:3:3:1. GLPs were prepared as a stock of $10 \mathrm{mg} / \mathrm{ml}$ in DMEM high glucose containing $10 \% \mathrm{FBS}$ and stored at $-20^{\circ} \mathrm{C}$.

Cytotoxic effects of GLPS on LoVo cells. As presented in Fig. 1, the inhibitory rates of GLPs $(0.313,0.625,1.25$, $2.5,5$ and $10 \mathrm{mg} / \mathrm{ml}$ ) at $72 \mathrm{~h}$ were $43.6,53.0,62.5,74.9$, 78.6 and $99.3 \%$, respectively, compared with the control. The half maximal inhibitory concentration $\left(\mathrm{IC}_{50}\right)$ values at 24 , 48 and $72 \mathrm{~h}$ were $6.94,1.67$ and $0.63 \mathrm{mg} / \mathrm{ml}$, respectively. The results demonstrate that GLPs significantly reduced cell viability in a dose- and time-dependent manner $(\mathrm{P}<0.01)$, suggesting that GLPs possess a potent cytotoxicity against human colon cancer cells.

GLPs inhibit cell migration in LoVo cells. At $48 \mathrm{~h}$, the scratch wounds were completely repaired by the migration of untreated cells, whilst the wounds were maintained in GLP-incubated cells as indicated by examination using light microscopy (Fig. 2A). In particular, LoVo cells treated with GLP concentrations of 5 and $10 \mathrm{mg} / \mathrm{ml}$ did not migrate towards the 
A

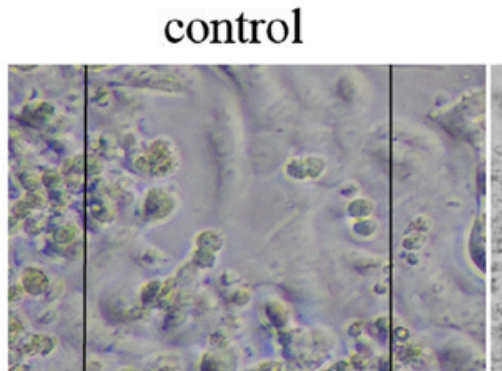

$0.625 \mathrm{mg} / \mathrm{ml}$

$1.25 \mathrm{mg} / \mathrm{ml}$

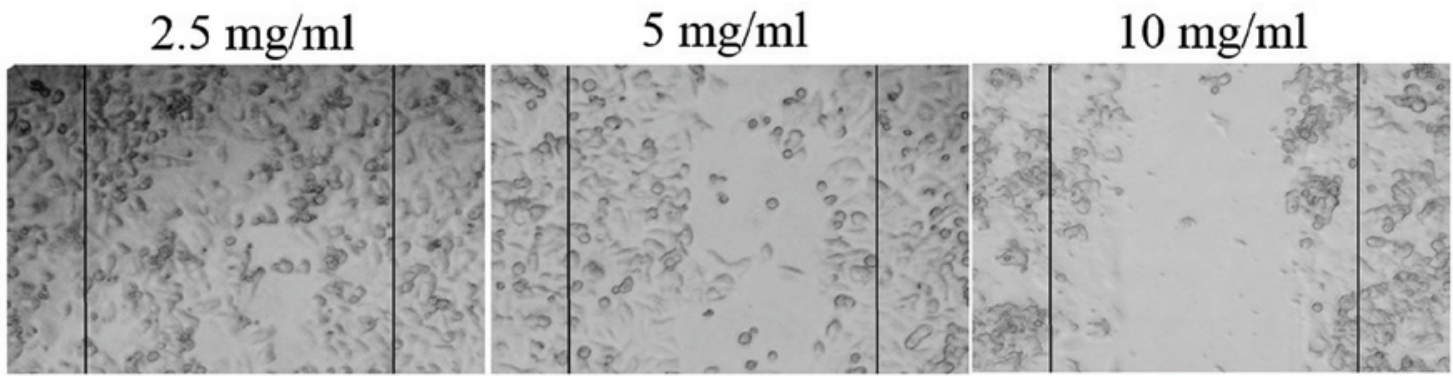

B

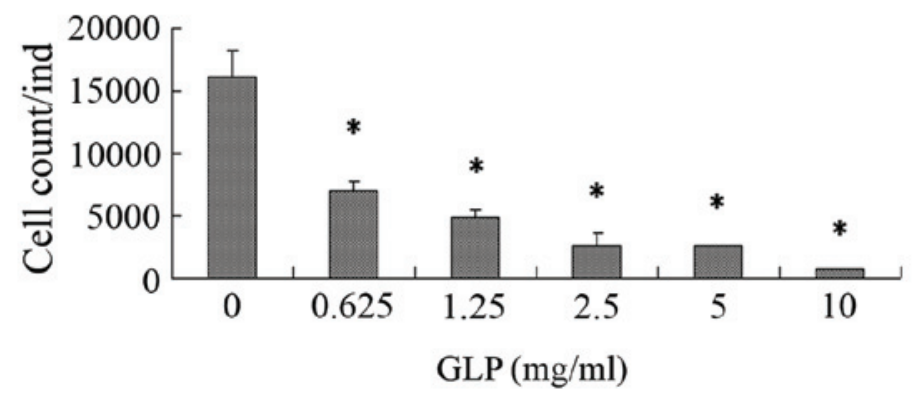

Figure 2. Effect of GLP concentration on the migration of LoVo cells. (A) Cells were visualized following a $48 \mathrm{~h}$ treatment with various concentrations of GLP (magnification, x100). The black vertical lines define the areas for counting migrated cells. (B) The number of migrated cells was quantitatively assessed using ImageJ software. Data presented as the mean \pm standard error; " $\mathrm{P}<0.01$ vs. control group. GLP, G. lucidum polysaccharide; Cell count/ind, cell count/index.

A

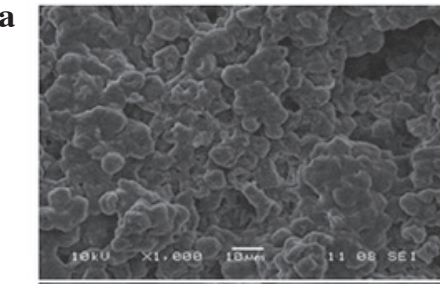

d

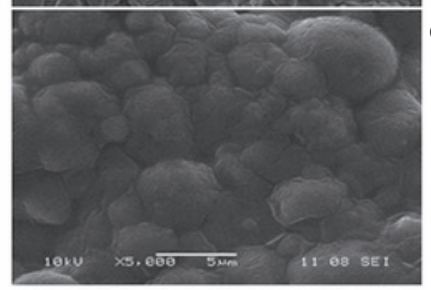

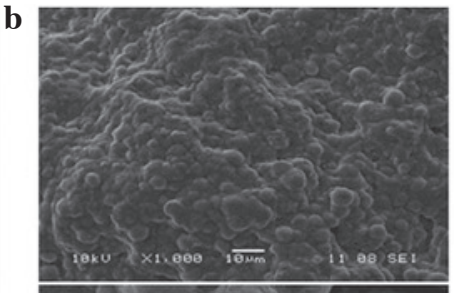

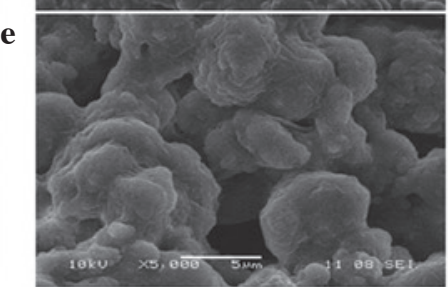

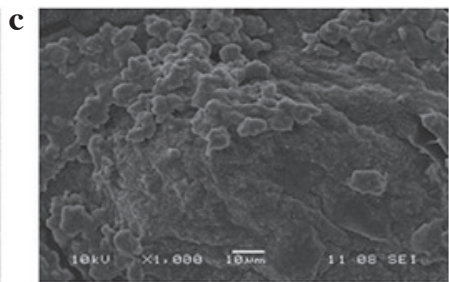

f

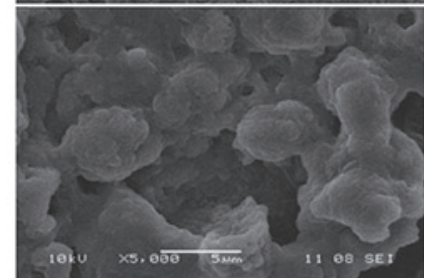

B
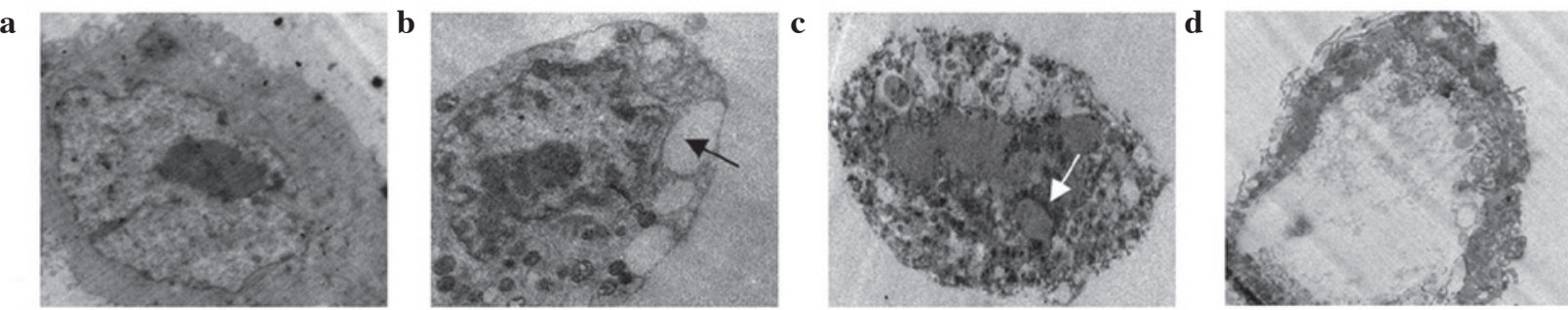

Figure 3. Effect of GLPs on the morphology of LoVo cells. Cells were exposed to 0,5 and $10 \mathrm{mg} / \mathrm{ml} \mathrm{GLP}$ for $48 \mathrm{~h}$. (A) Appearance of LoVo cells under scanning electron microscopy. (A-a-A-c) Magnification, x1,000; (A-d-A-f) magnification, x5,000. (B) Morphological observation of LoVo cells by transmission electron microscopy (magnification, x10,000). Black arrows, empty vacuole; white arrows, apoptotic bodies. GLP, G. lucidum polysaccharide. 
A

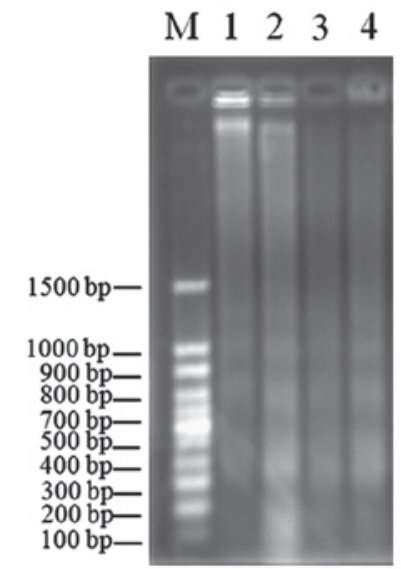

B

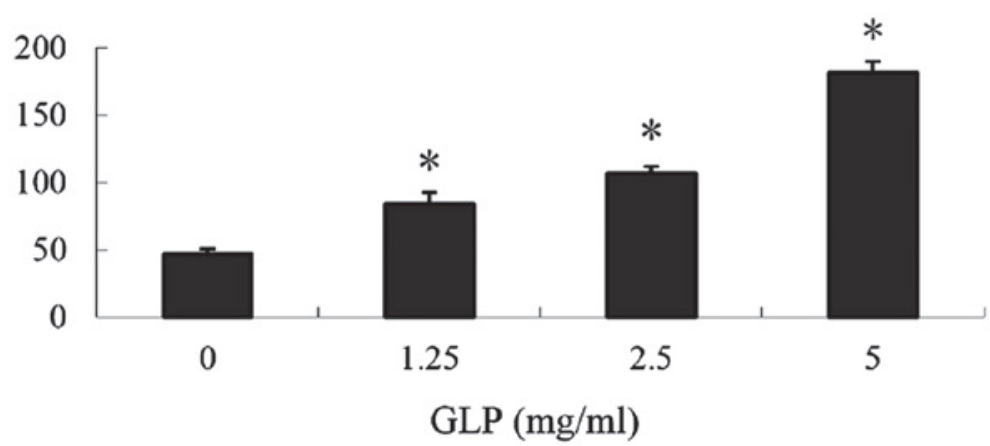

Figure 4. GLP-induced DNA fragmentation and LDH release in LoVo cells. (A) Cells were incubated with various concentrations of GLPs for 24 h, following which DNA was isolated and examined on a $1.2 \%$ agarose gel. Lane $1,10 \mathrm{mg} / \mathrm{ml} \mathrm{GLPs}$; lane $2,5 \mathrm{mg} / \mathrm{ml} \mathrm{GLPs}$; lane $3,2.5 \mathrm{mg} / \mathrm{ml} \mathrm{GLPs}$; lane $4,1.25 \mathrm{mg} / \mathrm{ml}$ GLPs. (B) LDH release was measured in GLP-treated and control cultures. Values are presented as the mean \pm standard deviation. ${ }^{*} \mathrm{P}<0.01$ vs. control group. GLP, G. lucidum polysaccharide; bp, base pairs; LDH, lactate dehydrogenase.

wound area compared with the untreated cells. As presented in Fig. 2B, exposure to GLPs $(0.625-10 \mathrm{mg} / \mathrm{ml})$ resulted in a reduction in the number of migratory cells from $95.9-56.9 \%$ $(\mathrm{P}<0.01)$, indicating that GLPs are able to dose-dependently suppress cell migration in LoVo cells.

GLP-mediated morphological alterations in LoVo cells. To investigate the cell death induced by GLPs, morphological characteristics of cells were observed by SEM and TEM. SEM observations demonstrated that untreated cells exhibited a uniform distribution and numerous microvilli on the cell surface (Fig. 3A-a and A-d). In GLP-treated cells, morphological alterations were observed including low cellular density (Fig. 3A-b and A-c), a reduction in the number or disappearance of microvilli and the formation of apoptotic bodies (Fig. 3A-e and A-f). In the TEM study, untreated cells displayed microvilli on the cell surface and a dispersed chromatin pattern (Fig. 3B-a). Following incubation with $5 \mathrm{mg} / \mathrm{ml}$ GLPs, the induction of cell death was indicated by cell shrinkage, microvilli loss, cell membrane blebbing (arrow in Fig. 3B-b) and cytoplasm marginalization (Fig. 3B-b). Subsequently, the cells broke up into membrane-bound apoptotic bodies (arrow in Fig. 3B-c). Following exposure to $10 \mathrm{mg} / \mathrm{ml}$ GLPs, apoptotic bodies were degraded by lysosomal enzymes (Fig. 3B-d).

Induction of DNA fragmentation and $L D H$ release by GLPS in LoVo cells. DNA fragmentation and the level of LDH released into the culture medium were used as indexes for evaluating apoptosis. The results demonstrated that GLPs induced DNA fragmentation following treatment with various doses of GLPs $(1.25-10 \mathrm{mg} / \mathrm{ml})$, presented in Fig. 4A. The LDH release assay demonstrated that GLP-induced LDH release was significantly increased $(\mathrm{P}<0.01)$, and this effect was dose-dependent (Fig. 4B), further supporting the role of apoptosis in GLP-mediated cytotoxicity.

Analysis of GLP-induced apoptotic pathways involved in LoVo cells. The addition of GLPs to cultured cells increased the activity of caspases-3, -8 and -9 in a dose-dependent manner $(\mathrm{P}<0.01)$, indicating GLP-mediated apoptosis occurred via

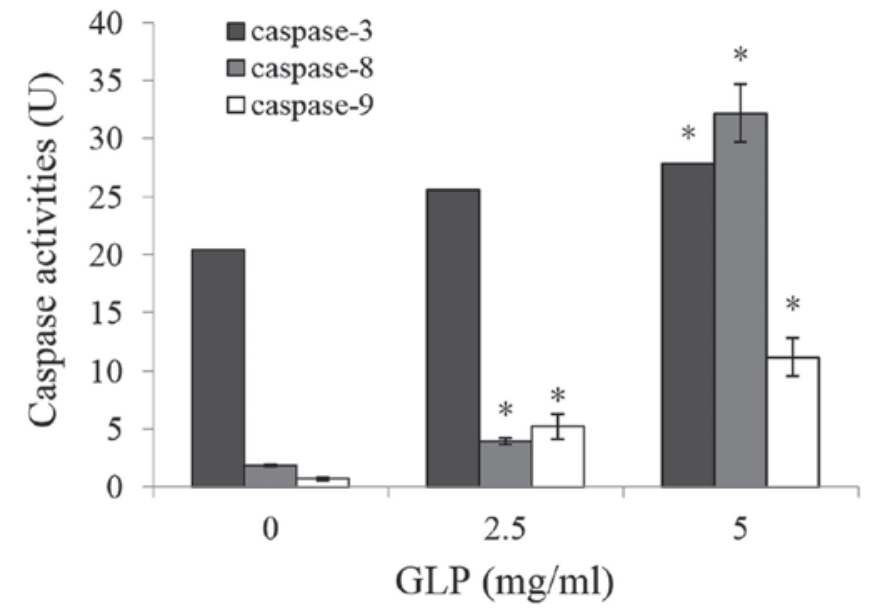

Figure 5. Activity of caspase-3, -8 and -9 in GLP-treated LoVo cells. Caspase activities of cells incubated with $0,2.5$ and $5 \mathrm{mg} / \mathrm{ml}$ GLPs for $48 \mathrm{~h}$. Values are presented as the mean \pm standard deviation of independent experiments performed in triplicate. " $\mathrm{P}<0.01$ vs. control group. GLP, G. lucidum polysaccharide.

the caspase-dependent pathway in LoVo cells (Fig. 5). Using western blotting, the effect of GLPs on the expression of proteins associated with apoptosis, including Fas, caspase-3 and poly(ADP-ribose) polymerase (PARP) was further investigated. As presented in Fig. 6, the level of caspase-3 protein was significantly increased compared with the control group at $12 \mathrm{~h}$ and reached its maximum level at $24 \mathrm{~h}$, which is in agreement with the results of caspase activity assay. In addition, the levels of Fas and PARP were increased and reduced, respectively, in a dose-dependent manner $(\mathrm{P}<0.01)$. These results suggest a possible association between GLP-induced apoptosis and the activation of the Fas/caspase-dependent pathway.

\section{Discussion}

As important ingredients in G. lucidum, GLPs have been demonstrated to reduce drug toxicity caused by chemotherapy (25), whilst additionally possessing antitumor 

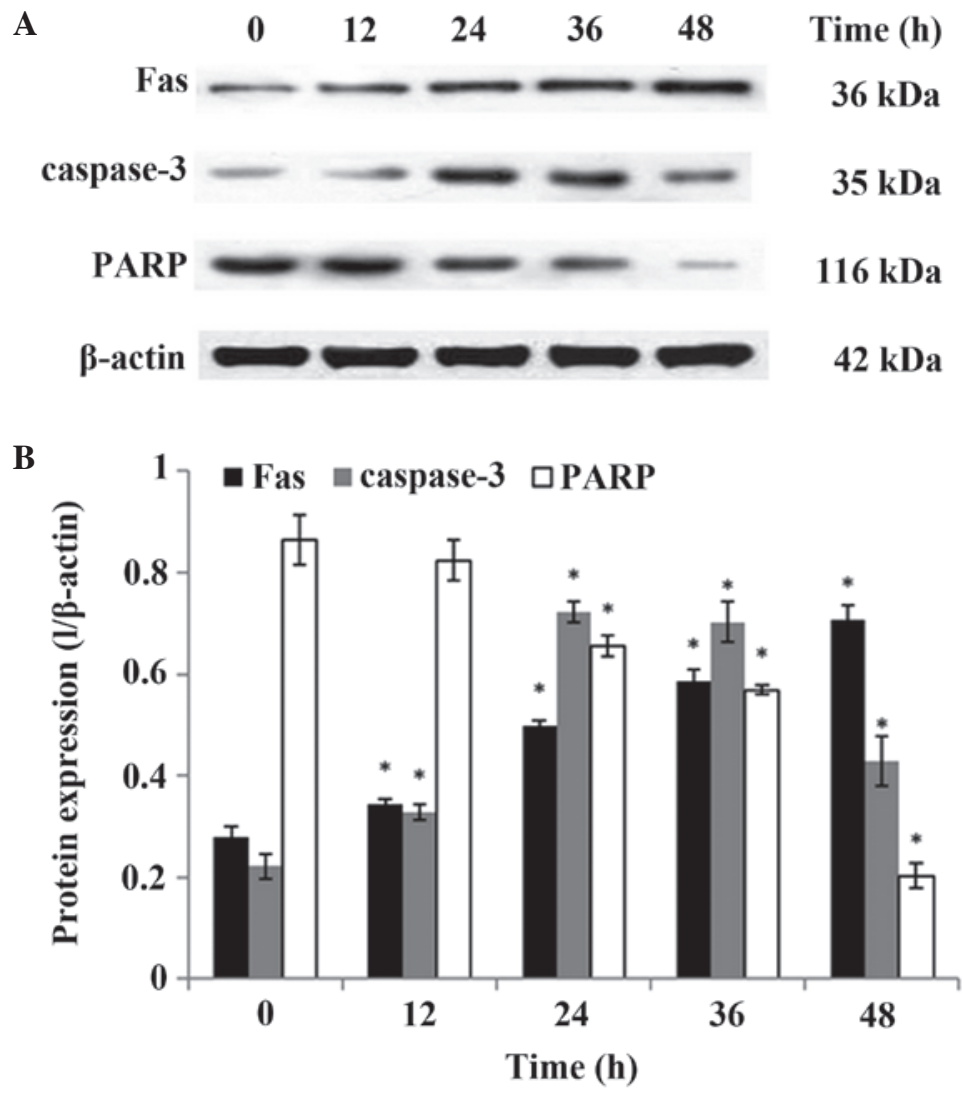

Figure 6. Effect of GLPs on the expression levels of proteins associated with apoptosis in LoVo cells. Cells were incubated with 5 mg/ml GLPs for the indicated time period $(0,12,24,36$ and $48 \mathrm{~h}$ ). The cell lysates were collected and subjected to western blot analysis. (A) Images of blots for Fas, caspase-3 and PARP antibody-bound proteins; (B) The histogram indicates that there were significant increases in Fas and caspase-3 protein levels and a significant reduction in PARP protein expression following GLP treatment. Values are expressed as the mean \pm standard deviation ( $\mathrm{n}=3$ ). $\mathrm{P}<0.01$ vs. control group. GLP, G. lucidum polysaccharide; PARP, poly(ADP) ribose polymerase.

activity without exhibiting adverse effects. These effects have been reported to be mediated through the activation of the immune response and the induction of apoptosis in a range of cancer cells $(26,27)$. The anticancer activity of polysaccharides is known to be affected by their chemical structure, chemical components, conformation, molecular mass and solubility in water $(28,29)$. In general, GLPs with a backbone of $\beta$-(1,3)-D-glucan and a high branching ratio, have been implicated to exhibit anticancer activity $(30,31)$. Additionally, high molecular weight GLPs exhibit greater antineoplastic activity than low molecular weight GLPs (32). Previous studies have demonstrated that GLPs, in addition to other chemical structures, possess anticancer effects in vitro and in vivo (33-35). GLPs comprising of 1,3-, 1,4- and 1,6-linked $\beta$-D-glucopyranosyl have been demonstrated to enhance the proliferation of $\mathrm{T}$ - and B-lymphocytes in vitro, and GLPs consisting of 1,4-linked $\alpha$-D-glucopyranosyl residues and 1,6-linked $\beta$-D-galactopyranosyl residues exhibited immune-stimulating activity in mice (36). Pan et al (37) isolated GLPs with a molecular weight of $78 \mathrm{kDa}$, which were composed of D-galactose, D-glucose and L-rhamnose in a molar ratio of 1.00:3.22:1.15. In the current study, GLPs (molecular weight $>10 \mathrm{kDa}$ ) with $\alpha$-glycosidic linkages were obtained from G. lucidum. The purified GLPs were predominantly composed of four kinds of monosaccharides, arabinose, galactose, glucose and cellose, at a molar ratio of 11:3:3:1, which was similar to a previous study (38). The anticancer effect on human colon cancer LoVo cells was investigated in the current study. In an MTT assay, 0.313-10 mg/ml GLPs demonstrated a time- and concentration-dependent inhibition of LoVo cells (Fig. 1), suggesting GLPs possess potential cytotoxic properties against LoVo cancer cells.

Cell migration serves an important role in numerous physiological processes, such as cell differentiation and proliferation (39). Unregulated cell migration is responsible for cancer formation, relapse and metastasis, ultimately leading to development of malignant tumors (40). Therefore, the inhibition of this process is a potential therapeutic strategy for controlling tumor growth. In the current study, significant suppression of migration was observed in the scratch-wound assay in LoVo cells following incubation with GLPs at doses of 0.625-10 mg/ml (Fig. 2). This demonstrated that GLPs additionally act as an inducer for migration inhibition in vitro.

Apoptosis serves a role in the suppression of tumor progression and elimination of unwanted cells in various biological systems, and serves a key role in cell death induced by anticancer drugs (41). Apoptotic cells exhibit characteristic morphological alterations including cell shrinkage, membrane blebbing, chromatin cleavage, formation of apoptotic bodies and nuclear condensation (42). In the current study, using electron microscopy (TEM and SEM), the ultrastructural alterations that indicate apoptosis were examined, including the appearance of pyknotic nuclei (chromatin condensation 
and marginalization), nuclear fragmentation and apoptotic body formation (Fig. 3). Following exposure of LoVo cells to GLPs, DNA fragments were observed, exhibiting exhibiting clear fragmentation by GLP treatment, particularly at 5 and $10 \mathrm{mg} / \mathrm{ml}$ GLP (Fig. 4A). Additionally, GLPs induced LDH release into the culture medium (Fig. 4B) (43). These observations indicate that apoptosis occurred in the LoVo human cancer cells upon treatment with GLPs, suggesting that GLPs may exert their anticancer effects on LoVo cells through an apoptotic pathway.

The organized process of apoptosis is controlled by a signaling network, which includes the following pathways: Mitogen-activated protein kinase/extracellular signal-related kinase, calpain/apoptosis inducing factor, mitochondrial and the death receptor pathways (44). Fas serves an important role in mediating apoptosis in the death receptor pathway. It stimulates an apoptotic signal by binding to Fas ligand (FasL) expressed on the surface of neighboring cells, which in turn results in the recruitment of specialized adaptor proteins and the activation of caspase cascades $(45,46)$. Increasing evidence suggests that activation of FasL/Fas may mediate activation downstream of caspase- 8 , followed by the activation of caspases-9 and -3 (47). Additionally, apoptosis is able to occur by the caspase- 8 independent FasL/Fas-mediated death receptor pathway (48). Mitochondria contain several potentially apoptogenic factors including cytochrome $c$ and pro-caspases-3 and -9 , which are associated with the mitochondrial apoptotic pathway $(49,50)$. Selenium-enriched GLP-induced apoptosis has been demonstrated to be associated with a reduction in the mitochondrial membrane potential, an increase in cytosolic levels of cytochrome $c$ and an increase in the activity of PARP, caspase-3 and caspase-9, with no obvious activation of caspase- 8 in human breast cancer cells (27). In the current study, to further understand the mechanisms of GLP-induced apoptosis in human colon cancer LoVo cells, the activity of caspases and the expression levels of proteins associated with apoptosis were investigated. These data indicated that GLPs significantly increased the activity of caspases-3, -8 and -9 in a time-dependent manner (Fig. 5). Additionally, GLP-induced apoptosis was observed to involve cleavage of PARP and the upregulation of Fas and caspase-3 (Fig. 6). It is conceivable that GLPs may exert their anticancer activity through the death receptor signaling pathway in LoVo cells.

In conclusion, GLPs exhibited significant cytotoxicity in LoVo cells in a time- and concentration-dependent manner. The anticancer effects of GLPs were associated with the induction of apoptosis and suppression of cell migration. In addition, these data demonstrate that GLPs induced apoptosis via a Fas/caspase- 8 dependent pathway. The current study provides a new perspective for further research on the toxicology and pharmacology of GLPs as a potential candidate for the treatment or prevention of colon cancer.

\section{Acknowledgements}

The authors would like to thank to Dr Zebin Huang who supplied the human colon cancer cells and would like to thank Professor Dongbo Liu and Professor Zhilan Xia for providing the G. lucidum.

\section{References}

1. Tokunaga T, Oshika Y, Abe Y, Ozeki Y, Sadahiro S, Kijima H, Tsuchida T, Yamazaki H, Ueyama Y, Tamaoki N, et al: Vascular endothelial growth factor (VEGF) mRNA isoform expression pattern is correlated with liver metastasis and poor prognosis in colon cancer. Br J Cancer 77: 998-1002, 1998.

2. Resnick MB, Routhier J, Konkin T, Sabo E and Pricolo VE Epidermal growth factor receptor, c-MET, beta-catenin, and p53 expression as prognostic indicators in stage II colon cancer: A tissue microarray study. Clin Cancer Res 10: 3069-3075, 2004.

3. Siegel R, Naishadham D and Jermal A: Cancer Statistics, 2013. Ca Cancer J Clin 63: 11-30, 2013.

4. Van Cutsem E, Nordlinger B and Cervantes A; ESMO Guidelines Working Group: Advanced colorectal cancer: ESMO Clinical Practice Guidelines for treatment. Ann Oncol 21 (Suppl 5): v93-v97, 2010.

5. Verweij J, Casali PG,Zalcberg J,LeCesne A, Reichardt P, Blay JY, Issels R, van Oosterom A, Hogendoorn PC, Van Glabbeke M, et al: Progression-free survival in gastrointestinal stromal tumours with high-dose imatinib: Randomised trial. Lancet 36: 1127-1134, 2004.

6. Gordon KB, Tajuddin A, Guitart J, Kuzel TM, Eramo LR and Vonroenn J: Hand-foot syndrome associated with liposome-encapsulated doxorubicin therapy. Cancer 75: 2169-2173, 1995.

7. Berkun Y, Levartovsky D, Rubinow A, Orbach H, Aamar S, Grenader T, Abou Atta I, Mevorach D, Friedman G and Ben-Yehuda A: Methotrexate related adverse effects in patients with rheumatoid arthritis are associated with the A1298C polymorphism of the MTHFR gene. Ann Rheum Dis 63: 1227-1231, 2004.

8. Venditto VJ and Simanek EE: Cancer therapies utilizing the camptothecins: A review of the in vivo literature. Mol Pharm 7: 307-349, 2010.

9. Bao B, Ali S, Banerjee S, Wang Z, Logna F, Azmi AS, Kong D, Ahmad A, Li Y, Padhye S, et al: Curcumin analogue CDF inhibits pancreatic tumor grow th by switching on suppressor microRNAs and attenuating EZH2 expression. Cancer Res 72: 335-345, 2012.

10. Tan W, Lu J, Huang M, Li Y, Chen M, Wu G, Gong J, Zhong Z, $\mathrm{Xu} \mathrm{Z}$, Dang Y, et al: Anti-cancer natural products isolated from chinese medicinal herbs. Chin Med 6: 27, 2011.

11. Harvey AL: Natural products in drug discovery. Drug Discov Today 13: 894-901, 2008.

12. Liu GT: Recent advances in research of pharmacology and clinical applications of Ganoderma P.Karst. species (Aphyllophoromycetideae) in China. Int J Med Mushrooms 17: 63-67, 2015.

13. Liu YJ, Shen J, Xia YM, Zhang J and Park HS: The polysaccharides from Ganoderma lucidum: Are they always inhibitors on human hepatocarcinoma cells? Carbohydr Polym 90: $1210-1215,2012$

14. Xu Z, Chen X,Zhong Z, Chen Land Wang Y: Ganoderma lucidum polysaccharides: Immunomodulation and potential anti-tumor activities. Am J Chin Med 39: 15-27, 2011.

15. Shen J, Park HS, Xia YM, Kim GS and Cui SW: The polysaccharides from fermented Ganoderma lucidum mycelia induced miRNAs regulation in suppressed HepG2 cells. Carbohydr Polym 103: 319-324, 2014

16. Li A, Shuai X, Jia Z, Li H, Liang X, Su D and Guo W: Ganoderma lucidum polysaccharide extract inhibits hepatocellular carcinoma growth by downregulating regulatory $\mathrm{T}$ cells accumulation and function by inducing microRNA-125b. J Transl Med 13: 100, 2015.

17. Guo L, Xie J, Ruan Y, Zhou L, Zhu H, Yun X, Jiang Y, Lü L, Chen K, Min Z, et al: Characterization and immunostimulatory activity of a polysaccharide from the spores of Ganoderma lucidum. Int Immunopharmacol 9: 1175-1182, 2009.

18. Zhu XL, Chen AF and Lin ZB: Ganoderma lucidum polysaccharides enhance the function of immunological effector cells in immunosuppressed mice. J Ethnopharmacol 111: 219-226, 2007.

19. Qu HG, Gao L, He D, et al: Effect of reversion of Ganoderma lucidum polysaccharides on cisplatin resistant in ovarian cancer cells and its mechanism. J Jilin Univ (Medicine Edition) 37: 251-255, 2011.

20. Liang Z, Yi YJ, Guo YT, Wang RC and Xiong XY: Effect of combined Ganoderma lucidum polysaccharides and flurouracil proliferation and apoptosis in human colon carcinoma HCT-116 cells. Food Sci 33: 310-314, 2012 (In Chinese). 
21. Staub AM: Removal of proteins Sevage method. Methods Carbohydr Chem 5: 5-6, 1965

22. Kochert G: Carbohydrate determination by the phenol-sulfuric acid method.In: Handbook of Phycological Methods, Vol II, Physiological and Biochemical Methods. Hellebust JA and Craigie JS (eds). Cambridge University Press, Cambridge, pp95-97, 1978.

23. Scott RW: Colorimetric determination of hexuronic acids in plant materials. Anal Chem 51: 936-941, 1979.

24. Li YQ, Fang L and Zhang KC: Structure and bioactivities of a galactose rich extracellular polysaccharide from submergedly cultured Ganoderma lucidum. Carbohydr Polym 77: 323-328, 2008

25. Hu Z, Chen X, Yang X, Gao Y and Zhou S: Water-soluble polysaccharides of Ganoderma lucidum (W.Curt.:Fr.) P. Karst. (Aphyllophoromycetideae) alleviate the dose-limiting toxicities of irinotecan (CPT-11). Int J Med Mushrooms 8: 321-328, 2006.

26. Zhou GQ, Zhao HY and Lu C: Effect of Ganoderma lucidum polysaccharides on intestinal mucosal immune system in $\mathrm{H} 22$ liver cancer bearing mice. Zhongguo Zhong Xi Yi Jie He Za Zhi 29: 335-339, 2009 (In Chinese).

27. Shang D, Li Y, Wang C, Wang X, Yu Z and Fu X: A novel polysaccharide from Se-enriched Ganoderma lucidum induces apoptosis of human breast cancer cells. Oncol Rep 25: 267-272, 2011.

28. Ooi VE and Liu F: Immunomodulation and anti-cancer activity of polysaccharide-protein complexes. Curr Med Chem 7: 715-729, 2000

29. Xu W, Zhang F, Luo Y, Ma L, Kou X and Huang K: Antioxidant activity of a water-soluble polysaccharide purified from Pteridium aquilinum. Carbohydr Res 344: 217-222, 2009.

30. Miyazaki T and Nishijima M: Studies on fungal polysaccharides. XXVII. Structural examination of a water-soluble, antitumor polysaccharide of Ganoderma lucidum. Chem Pharm Bull (Tokyo) 29: 3611-3616, 1981.

31. Mizuno T, Wang G, Zhang J, Kawagishi H, Nishitoba T and Li J: Reishi, Ganoderma lucidum and Ganoderma tsugae: Bioactive substances and medicinal effects. Food Rev Int 11: 151-166, 1995.

32. Zhang L, Zhang M, Zhou Q, Chen J and Zeng F: Solution properties of antitumor sulfated derivative of $\alpha-(1-->3)$-D-glucan from Ganoderma lucidum. Biosci Biotechnol Biochem 64: 2172-2178, 2000.

33. Kimura Y, Taniguchi M and Baba K: Antitumor and antimetastatic effects on liver of triterpenoid fractions of Ganoderma lucidum: Mechanism of action and isolation of an active substance. Anticancer Res 22: 3309-3318, 2002.

34. Tang W, Liu JW, Zhao WM, Wei DZ and Zhong JJ: Ganoderic acid T from Ganoderma lucidum mycelia induces mitochondria mediated apoptosis in lung cancer cells. Life Sci 80: 205-211, 2006.

35. Weng CJ and Yen GC: The in vitro and in vivo experimental evidences disclose the chemopreventive effects of Ganoderma lucidum on cancer invasion and metastasis. Clin Exp Metastas 27: 361-369, 2010.
36. Bao XF, Wang XS, Dong Q, Fang JN and Li XY: Structural features of immunologically active polysaccharides from Ganoderma lucidum. Phytochemistry 59: 175-181, 2002.

37. Pan D, Wang L, Chen C, Teng B, Wang C, Xu Z, Hu B and Zhou P: Structure characterization of a novel neutral polysaccharide isolated from Ganoderma lucidum fruiting bodies. Food Chem 135: 1097-1103, 2012.

38. Chan WK, Cheung CC, Law HK, Lau YL and Chan GC: Ganodermalucidum polysaccharidescan induce human monocytic leukemia cells into dendritic cells with immuno-stimulatory function. J Hematol Oncol 1: 9, 2008.

39. Doyle AD, Petrie RJ, Kutys ML and Yamada KM: Dimensions in cell migration. Curr Opin Cell Biol 25: 642-649, 2013.

40. Condeelis J and Pollard JW: Macrophages: Obligate partners for tumor cell migration, invasion, and metastasis. Cell 124: 263-266, 2006.

41. Surh YJ: Cancer chemoprevention with dietary phytochemicals. Nat Rev Cancer 3: 768-780, 2003.

42. Doonan F and Cotter TG: Morphological assessment of apoptosis. Methods 44: 200-204, 2008.

43. Sun B, Cai Y,Li Y,Li J,Liu K, Li Y and Yang Y: The nonstructural protein NP1 of human bocavirus 1 induces cell cycle arrest and apoptosis in Hela cells. Virology 440: 75-83, 2013.

44. Nguyen TTT, Tran E, Nguyen TH, Do PT, Huynh TH and Huynh H: The role of activated MEK-ERK pathway in quercetin-induced growth inhibition and apoptosis in A549 lung cancer cells. Carcinogenesis 25: 647-659, 2004.

45. Chu K, Niu X and Williams LT: A Fas-associated protein factor, FAF1, potentiates Fas-mediated apoptosis. Proc Natl Acad Sci USA 92: 11894-11898, 1995.

46. Huang DC, Hahne M, Schroeter M, Frei K, Fontana A, Villunger A, Newton K, Tschopp J and Strasser A: Activation of Fas by FasL induces apoptosis by a mechanism that cannot be blocked by Bcl-2 or Bcl-x(L). Proc Natl Acad Sci USA 96: 14871-14876, 1999.

47. Li H, Zhu H, Xu CJ and Yuan J: Cleavage of BID by caspase 8 mediates the mitochondrial damage in the Fas pathway of apoptosis. Cell 94: 491-501, 1998.

48. Xiong J, Cheng G, Tang $\mathrm{H}$, Zhen $\mathrm{HN}$ and Zhang X: Ardipusilloside I induces apoptosis in human glioblastoma cells through a caspase-8-independent FasL/Fas-signaling pathway. Environ Toxicol Pharmacol 27: 264-270, 2009.

49. Larrosa M, Tomás-Barberán FA and Espín JC: The dietary hydrolysable tannin punicalagin releases ellagic acid that induces apoptosis in human colon adenocarcinoma Caco-2 cells by using the mitochondrial pathway. J Nutr Biochem 17: 611-625, 2006.

50. Fulda S and Debatin KM: Extrinsic versus intrinsic apoptosis pathways in anticancer chemotherapy. Oncogene 25: 4798-4811, 2006. 